\title{
Производственная культура рабочих современной России как элемент их человеческого капитала (этнометрический анализ на основе концепции Г. Хофстеда) ${ }^{1}$
}

\author{
Н.В. ЛАТОВА*
}

*Наталия Валерьевна Латова - кандидат социологических наук, старший научный сотрудник, Институт социологии РАН. Адрес: 117218, Москва, ул. Кржижановского, д. 24/35, к. 5. E-mail: myshona@rambler.ru

Цитирование: Латова Н.В. (2017) Производственная культура рабочих современной России как элемент их человеческого капитала (этнометрический анализ на основе концепции Г. Хофстеда) // Мир России. Т. 26. № 3. С. 36-63. DOI: $10.17323 / 1811-038 X-2017-26-3-36-63$

В статье рассматриваются особенности производственной культуры отдельных профессиональных групп российских работников с преимущественным вниманием к производственной (организационной) культуре рабочих как особой группь. Для определения культурной специфики разных профессиональных групп использована этнометрическая методика Г. Хофстеда (VSM94). Исследование показало, что по своим культурным характеристикам российская нация относительно гомогенна и почти равно удалена и от стран Востока, и от стран Запада. Определенный разброс по отдельным показателям 8 группах работников не создает в ней центробежного эффекта: в иелом четыре основные профессиональные группь (спещиалисты, служащие и госслужащие, работники торговли и бытовых услуг, а также рабочие) достаточно близки друг к другу и далеко отстоят от аналогичных групп в зарубежных государствах. В определенной мере этим группам противостоит группа предпринимателей, самозанятых и руководителей, культурные установки которых гораздо ближе к западному менталитету, хотя и не идентичны ему.

Делается вывод, что культурная спещифика рабочих России во многом перекликается со спецификой рабочих как сочиальной группь в зарубежных странах. Общим является более сильная, чем у предпринимателей и руководителей, ориентация рабочих на проявление иерархии и более слабые достижительные мотивации.

\footnotetext{
1 Исследование выполнено при финансовой поддержке РФФИ, проект «Человеческий капитал российских рабочих: состояние, динамика, факторы», № 16-03-00098.
} 
Производственная культура российских рабочих, отражающаяся в культурных показателях Г. Хофстеда, хорошо сочетается с исконно российской высокоэффективной организачией труда в форме артелей, и, судя по полученным данным, очень устойчива, поэтому продуктивнее не уничтожать устоявшиеся формы трудовой деятельности, а использовать традииионные российские формы менеджмента.

Ключевые слова: этнометрия, производственная культура, человеческий капитал, рабочие, Хофстед, артельный принцип организации труда, культурная специфика россиян

\section{Возможен ли этнометрический взгляд на рабочий класс?}

Связь между экономической теорией и социально-экономической политикой кажется достаточно очевидной: теория обобщает универсальные принципы рационального поведения и становится, в свою очередь, методологической основой для разработки экономической политики не только отдельных фирм и компаний, но и государства в целом. Однако в странах примерно равного уровня развития и хозяйственное поведение людей, и структуры бизнеса, и экономическая политика редко оказываются одинаковыми: каждая страна ищет и находит свои варианты решения универсальных проблем, поскольку экономическая теория определяет лишь спектр (коридор возможностей) допустимых решений. Но какие именно из них целесообразно выбрать в каждом конкретном случае? Представления о том, что заимствование успешных институтов автоматически даст положительный результат в любой стране, давно стали архаикой. Сейчас большинство обществоведов соглашается с тем, что нельзя сбрасывать со счетов культурные особенности, заданные «зависимостью от предшествующего развития» (path dependence) [Харрисон, Хантингтон 2002]. Таким образом, выбор правильного решения во многом опосредован пониманием тех культурных отличительных черт, в рамках которых это решение и будет затем реализовано.

В течение последних 20 лет российское обществоведение постоянно пополнялось этнометрическими исследованиями ${ }^{2}$, в которых анализировалась кросс-культурная специфика различных социальных групп с использованием формализованных методов измерения. За этот период были апробированы самые разные зарубежные методики. В частности, российские результаты проекта Global Leadership and Organizational Behavior Effectiveness (GLOBE) были представлены в работах М.В. Грачева [Грачев 1999; Grachev 2009]; данные по России, полученные в проекте World Values Survey (WVS) [Инглхарт 2002; Инглхарт, Вельиель 2011], с 2011 г. активно популяризируются и дополняются в Лаборатории сравнительных социальных исследований Национального исследовательского университета «Высшая школа экономики»³; методика Ш. Шварца Schwartz Value Survey

\footnotetext{
2 Под этнометрическими исследованиями (этнометрией) понимается направление этносоциальных исследований, анализирующих кросс-культурную специфику различных социальных (прежде всего национальных и этнических) групп с использованием формализованных методов измерения.

3 http://lcsr.hse.ru
} 
(SVS) регулярно используется в работах под руководством Н.М. Лебедевой [Лебедева, Татарко 2007; Lebedeva, Tatarko 2012; Цой, Лебедева, Татарко 2016] и B.C. Магуна [Магун, Руднев 2010; Магун, Руднев, Шмидт 2015; Magun, Rudnev, Schmidt 2016]; на основе методики Г. Хофстеда Values Survey Modules (VSM) проводятся исследования в Институте социологии РАН [Латова, Латов 2001; Данилова, Тарарухина 2003; Латова, Тихонова 2010; Danilova, Yadov 2010].

Многие проекты, связанные с этнометрическими исследованиями, фокусируются на макроуровне, т.е. на определении культурных особенностей россиян в целом. Однако есть и такие, которые изучают культурные характеристики на мезоуровне, т.е. на уровне отдельных элементов нации и групп населения. Такой подход полностью правомерен и обоснован основоположником этнометрии Г. Хофстедом, по мнению которого, каждому человеку присущи определенные образцы (паттерны) мышления, эмоциональных переживаний и реальных действий. Они формируются в основном в раннем детстве, когда люди наиболее восприимчивы к обучению. Сознательно используя аналогию с программированием компьютера, Г. Хофстед пишет, что «такого рода паттерны мышления, чувств и действий называются ментальными программами или $<\ldots>$ программным обеспечением мышления ${ }^{4} \gg$ [Hofstede G., Hofstede G.J., Minkov 2010, p. 5]. Эти ментальные программы проявляются как культурная специфика человека, оказывают прямое воздействие на качество его человеческого капитала'. При этом содержание этих программ связано с разными социальными ролями и идентификациями личности - национальной, этно-религиозной, половозрастной, профессиональной и т.д. Определяющей (и в этом смысле базовой) является обычно культурно-национальная идентичность, обусловленная принадлежностью индивида к стране/нации. Именно для ее исследования и предназначены в первую очередь этнометрические методики. Такие идентичности, как региональная, этническая и религиозная, по механизму формирования близки к национальной и поэтому могут изучаться аналогичным инструментарием. Что касается половозрастного и профессионального аспектов, то они формируются несколько отличным от национальной идентичности способом (например, общность территории или языка здесь не играет существенной роли), однако частично также могут быть описаны посредством показателей, применимых к национальным культурным особенностям. Другими словами, этнометрические методики не только работают при анализе национального культурного своеобразия, но подходят и для изучения, например, отдельных профессиональных групп.

В центре внимания нашего исследования находятся именно специфические черты производственной культуры отдельных профессиональных групп российских работников, а более конкретно - производственная (или организационная) культура рабочих как особой профессиональной группы. Интерес к этой группе обусловлен рядом факторов.

Во-первых, за время существования этнометрических методик проведено довольно много исследований национальных культурных особенностей. Однако, по признанию Г. Хофстеда, основным контингентом его базовой работы

4 В оригинале - software of the mind.

5 Понятие «человеческий капитал» используется в его классической трактовке [Беккер 2003]. 
в IBM, а также других исследований, основанных на предложенной им методике, в преобладающем большинстве являлись представители среднего класса. Не вдаваясь в подробности различий и способов определения среднего и рабочего классов, признаем, что средний класс даже в развитом западном обществе не представляет общество в целом. Что касается России, то отечественный рабочий класс - это одна из крупнейших социальных групп. Если обратиться к статистике, то в ядро рабочего класса (т.е. тех, кто несомненно попадает в эту категорию) по состоянию на октябрь 2015 г. входит 41\% всех занятых (неквалифицированные рабочие - $12 \%$, операторы производственных установок и машин, сборщики и водители - 15\%, квалифицированные рабочие промышленности, строительства, транспорта и рабочие родственных занятий - 14\%) [Сведения о заработной плате 2016, таблица 6]. Таким образом, знание о национальных культурных особенностях россиян обязательно предполагает учет этой многочисленной группы работников.

Во-вторых, вопреки тому факту, что показатели национальной культуры можно применять для установления различий в профессиональном срезе, научных работ, посвященных этой интересной теме, практически нет. Наблюдается определенный парадокс: сами различия были впервые зафиксированы Г. Хофстедом еще в 1977 г. [Hofstede 2001, p. 88], причем именно на производственных коллективах и для целей управления, однако до сих пор на эту тему ученые в основном только теоретизируют [Kohun, Skovira, Burcik, DeLorenzo 2014; Taras, Steel, Kirkman 2016]. Те единичные работы, которые встречаются в иностранной научной литературе и основаны на эмпирическом материале, затрагивают проблему производственной культуры разных профессиональных групп лишь касательно, в привязке к другой исследовательской задаче. Кроме того, спектр рассматриваемых профессиональных групп в них настолько несущественен, что предоставляет сильно ограниченные шансы для каких-либо значимых выводов [Kuchinke 1999; Nistor, Lerche, Weinberger, Ceobanu, Heymann 2014]. В отечественной науке ситуация лучше: несмотря на то, что методологию Г. Хофстеда в России использует ограниченное количество ученых, они уже обратили внимание не только на возможности изучения национальной культуры россиян, но и на перспективы анализа характеристик этой культуры в профессиональном аспекте [Данилова, Тарарухина 2003]. Действительно, если культурная специфика разных профессиональных групп не совпадает, то можно предположить, что и система менеджмента должна соответствовать не только культурным отличиям нации в целом, но и учитывать ту профессиональную среду, на которую она в итоге рассчитана.

И, наконец, в-третьих, сложная экономическая ситуация, в которой оказалась Россия, а также взятый ею курс на импортозамещение резко актуализировали необходимость исследования состояния рабочего класса как одного из ключевых субъектов, призванных повысить эффективность функционирования реального сектора экономики страны. Анализ культурных особенностей (сильных и слабых сторон производственной культуры) рабочих даст шанс глубже понять их характеристики как одного из ключевых элементов социально-профессиональной структуры общества, а также позволит очертить тот «коридор возможностей», которым ограничено не только реформирование российской экономики, но и общее социально-политическое развитие общества в ближайшие десятилетия. 


\section{Этнометрический «квартет» Г. Хофстеда: PDI, IDV, MAS и UAI}

В качестве рабочего инструментария в нашем исследовании была выбрана методика Г. Хофстеда «Модуль исследования ценностей 1994» (Value Survey Module 1994 - VSM94). У методики VSM есть несколько вариантов (последний относится к 2013 г.), однако только версия VSM94 просуществовала в неизменном виде 14 лет, все остальные довольно быстро ушли в архив (как правило, ввиду введения и/или уточнения новых показателей) [Hofstede, Minkov 2013]. Кроме того, именно VSM94, с одной стороны, дала возможность вписать новые данные в контекст базовой работы Г. Хофстеда, а с другой, адаптировала инструментарий таким образом, что он стал применим не только к работающим респондентам, но и к тем, кто только собирается выйти на рынок труда.

Сначала разберемся в особенностях и эвристических возможностях методики VSM94 с акцентом на анализ производственной культуры разных профессиональных групп. Изучая ментальные программы, Г. Хофстед использовал четыре основных этнометрических показателя: «Дистанция власти», «Индивидуализм», «Маскулинность» и «Избегание неопределенности».

«Дистанция власти» (PDI - Power Distance) - показатель того, насколько люди готовы принимать неравномерность распределения власти в различных организациях, то есть их лояльность к властной вертикали, где основной объем главенствующих полномочий концентрируется на верхних уровнях. Что касается профессиональной структуры, то «Дистанция власти» проявляется у представителей различных профессий неодинаково. Проведенные Г. Хофстедом исследования данных, собранных в Великобритании, Франции и Германии, показали, что представители профессий, сопряженных с низким статусом и образовательным уровнем (неквалифицированные и малоквалифицированные рабочие), имеют заметно более высокий показатель «Дистанции власти», чем те, у кого профессия связана с высоким статусом и образовательным уровнем (например, инженер или ученый). Причем в кросс-культурном разрезе наблюдалась интересная закономерность: в странах с общей низкой «Дистанцией власти» различие показателей в профессиональном разрезе было более выраженным, чем в странах с высокой «Дистанцией власти». Другими словами, в более авторитарном обществе наличие властной вертикали воспринимается как норма вне зависимости от профессии. Однако в странах, ориентированных на равенство и независимость, эти ценности больше присущи высококвалифицированным работникам, в то время как представители малоквалифицированных профессий по этому параметру ближе к своим коллегам из стран с высоким показателем «Дистанции власти».

«Индивидуализм» (IDV - Individualism) - показатель того, предпочитают ли люди заботиться только о себе и собственных семьях либо имеют склонность объединяться в более крупные группы, которые несут ответственность за человека в обмен на его лояльность группе. По мнению Г. Хофстеда, показатель «Индивидуализм» в профессиональном разрезе не проявляется. Точнее говоря, между представителями разных профессий в принципе есть различие в том, что одни ориентированы на индивидуальную инициативу, а другие - на групповую лояльность, но методика VSM этот нюанс на доступных Г. Хофстеду данных не улавливает. 
«Маскулинность» (MAS - Masculinity) - показатель склонности людей к напористости и жесткости, их сосредоточенности на материальном успехе, отсутствии интереса к другим людям и условиям их жизни, к межличностным отношениям как таковым. Речь идет о том, являются ли в рамках определенной культуры наиболее важными так называемые мужские ценности («настойчивость», «уверенность в себе», «успех и конкуренция») или женские («жизненные удобства», «поддержание теплых личных отношений», «забота о слабых», «солидарность»). В соответствии с результатами, полученными Г. Хофстедом, дихотомия «Маскулинность» - «Феминность» вполне применима к профессиональной структуре, хотя проявления показателя «Маскулинность» в профессиональном срезе более специфичны, чем, например, у «Дистанции власти». Если «Дистанция власти» непосредственно коррелирует с уровнем квалификации, то в случае с «Маскулинностью» такая зависимость отсутствует. Главными факторами, которые влияют на различия между представителями разных профессий по показателю «Маскулинность», являются наличие/отсутствие конкуренции и зависимость итогового заработка от достигнутых результатов.

«Избегание неопределенности» (UAI - Uncertainty Avoidance) - показатель того, насколько люди проявляют нетерпимость к неясным ситуациям и рискам, пытаются уклониться от них посредством выработки четких правил, веря в их абсолютную оправданность и отказываясь терпеть девиантное поведение. Несмотря на то, что логически довольно легко выделить профессии, связанные с наличием строгих предписаний (например, работник банка), и противоположные профессии, требующие риска и гибкости поведения (журналист), анализ Г. Хофстедом полученных данных не показал различий между профессиями по показателю «Избегание неопределенности» в рамках одних и тех же культур.

\section{Российский рабочий: европеец или азиат?}

Насколько эти закономерности, тенденции и культурная специфика, в том числе и различных социально-профессиональных групп, проявляются в России? Ответ на этот вопрос мы попытались получить, используя базу данных всероссийского исследования «Готово ли российское общество к модернизации?», проведенного в 2010 г. коллективом ученых Института социологии РАН под руководством М.К. Горшкова и Н.Е. Тихоновой ${ }^{6}$ Опрос охватил 1684 респондента в возрасте от 18 лет и старше, жителей всех типов поселений и территориально-экономических районов РФ, представлявших основные социально-профессиональные группы населения. При анализе культурных характеристик России в целом использовался общий массив данных, для изучения культурных особенностей работающих россиян была задействована подвыборка работников, т.е. из выборки исключались

6 Отметим, что выбор массива 2010 г. обусловлен отчасти особенностями инструментария соответствующего исследования (использована оригинальная методика Г. Хофстеда VSM94), отчасти - стабильностью и оптимизмом, характерными для этого года (см. [Латова (1) 2016, с. 51]). С одной стороны, кризис 2008 г. уже сменился экономическим ростом, а с другой, еще не начались протестные политические выступления 2011-2013 гг. Таким образом, можно говорить, что в 2010 г. культурная специфика россиян была представлена не замутненной политическими и экономическими катаклизмами. 
студенты, а также неработающие (в т.ч. пенсионеры) и безработные. Общая численность подмассива работающих составила 1288 чел., среди которых рабочих насчитывалось 550 чел.

Следует подчеркнуть, что культурные показатели, которые лежат в основе этнометрического анализа, не применимы на индивидуальном уровне. Сам Г. Хофстед по этому поводу заметил: «Первичный анализ базы данных на уровне индивидуальных респондентов привел к достаточно невразумительным результатам. Определенного прорыва удалось добиться, лишь когда внимание было направлено на установление корреляции средних значений результатов обзора на уровне стран» [Хофстеде 2014, с. 15]. Таким образом, важно понимать, что показатели Хофстеда представляют собой средние значения (среднее арифметическое), вычисляемые для определенного социума/группы. Безусловно, реальные показатели отдельных представителей группы могут очень сильно различаться между собой и варьироваться по среднему показателю в группе. Личностные показатели не имеют в этнометрических исследованиях самостоятельного смысла, однако они способны продемонстрировать, насколько культурные показатели отдельных индивидов отличаются от средних показателей группы. Мы не можем ожидать, что культурные показатели всех индивидов в группе будут единообразны, но надо иметь представление, как проявляется это разнообразие у большей части представителей группы, составляющих ядро рассматриваемого сообщества.

Основываясь на методе Г. Хофстеда, вычислим показатели культурных характеристик для разных профессиональных групп современных россиян, а также определим характер распределения признака в каждой из групп, используя перцентильные размахи $(\mathrm{Rp})^{7}$ (таблица 1).

Анализируя данные таблицы 1, можно разобраться, насколько гомогенны группы разных категорий работников с точки зрения характеристик их производственной культуры. Чтобы определить концентрацию признака в исследуемых группах, рассмотрим перцентильные размахи. Сравнивая между собой Rp отдельных показателей у работающих россиян в целом, отметим, что наиболее заметная вариация признака наблюдается по «Избеганию неопределенности» $(\mathrm{Rp}=130)$ и особенно по «Маскулинности» $(\mathrm{Rp}=180)$, а у остальных двух показателей размах колебаний признака вокруг среднего арифметического заметно меньше $\left(\mathrm{Rp}_{\text {«Дистанция власти» }}=105\right.$ и $\left.\mathrm{Rp}_{\text {«индивидуализм» }}=100\right)$. Что же касается отдельных профессиональных групп, то, как видно из таблицы 1, на фоне остальных групп:

- у предпринимателей, самозанятых и руководителей разного уровня самый большой размах признака отмечается по показателю «Избегание неопределенности»;

- у специалистов - по показателю «Дистанция власти»;

- у служащих и госслужащих большие вариации демонстрирует «Маскулинность»;

- работники торговли и бытовых услуг сильнее, чем все остальные, различаются по «Индивидуализму».

\footnotetext{
7 Так как в данном случае нас интересовали не выбросы (крайние показатели), а концентрация признака около средней, мы решили рассмотреть вариацию/размах показателя у 66\% (т.е. почти у 2/3) представителей каждой группы, параметры которых сконцентрированы вокруг среднего арифметического.
} 
Таблица 1. Показатели культурной специфики разных категорий работников, баллы ${ }^{8}$

\begin{tabular}{|c|c|c|c|c|}
\hline Категория работников & $\begin{array}{l}\text { Дистанция } \\
\text { власти (PDI) }\end{array}$ & $\begin{array}{l}\text { Индивидуализм } \\
\text { (IDV) }\end{array}$ & $\begin{array}{l}\text { Маскулинность } \\
\text { (MAS) }\end{array}$ & $\begin{array}{c}\text { Избегание } \\
\text { неопреде- } \\
\text { ленности (UAI) }\end{array}$ \\
\hline \multirow[t]{2}{*}{ Работающие россияне в целом } & 28 & 62 & 33 & 96 \\
\hline & $105[80,-25]^{8}$ & $100[105,5]$ & $180[110,-70]$ & $130[160,30]$ \\
\hline \multirow{2}{*}{$\begin{array}{l}\text { Предприниматели, } \\
\text { самозанятые и руководители } \\
\text { разного уровня }(\mathrm{N}=121)\end{array}$} & 9 & 73 & 41 & 86 \\
\hline & $100[50,-50]$ & $84[105,21]$ & $161[131,-30]$ & $148[170,22]$ \\
\hline \multirow[t]{2}{*}{$\begin{array}{l}\text { Специалисты, в т.ч. военные } \\
(\mathrm{N}=282)\end{array}$} & 31 & 61 & 32 & 102 \\
\hline & $110[82,-28]$ & $113[105,-8]$ & $170[120,-50]$ & $115[160,45]$ \\
\hline \multirow[t]{2}{*}{$\begin{array}{l}\text { Служащие, госслужащие } \\
(\mathrm{N}=151)\end{array}$} & 31 & 58 & 24 & 96 \\
\hline & $99[80,-19]$ & $100[105,5]$ & $200[90,-110]$ & $131[181,50]$ \\
\hline \multirow[t]{2}{*}{$\begin{array}{l}\text { Работники торговли и } \\
\text { бытовых услуг (N=184) }\end{array}$} & 25 & 65 & 40 & 101 \\
\hline & $108[93,-15]$ & $125[105,-20]$ & $178[118,-60]$ & $125[155,30]$ \\
\hline \multirow[t]{2}{*}{ Рабочие (N=550) } & 30 & 59 & 32 & 94 \\
\hline & $100[75,-25]$ & $100[105,5]$ & $186[110,-76]$ & $135[160,25]$ \\
\hline
\end{tabular}

8 Перцентильный размах (Rp) рассчитывался как разница максимального показателя в группе респондентов (33\% от всей группы), имеющих значение выше среднего арифметического, и минимального показателя в группе респондентов (еще 33\% от всей группы), у которых значение было ниже среднего арифметического. В итоге мы получили размах показателя у 66\% представителей группы, которая равномерно сконцентрирована вокруг среднего значения, т.е. вокруг культурного показателя Г. Хофстеда. Рассмотрим для примера показатель «Дистанция власти» у работающих россиян в целом. Его максимальное значение для 33\% всех работающих, имеющих данный показатель больше 28 баллов (среднее значение по группе), составило 80 баллов, а минимальное значение для 33\% всех работающих, у которых этот культурный показатель было меньше 28 баллов, оказалось равно -25 баллам. В итоге перцентильный размах для 66\% работающих вычислялся следующим образом: $\mathrm{Rp}=80$ - (-25)= 105 баллов. Аналогичным образом рассчитывались все остальные перцентильные размахи. 
Разброс по «Избеганию неопределенности» в группе предпринимателей, самозанятых и руководителей разного уровня можно объяснить тем, что в данную группу оказались несколько искусственно объединены люди с довольно разными modus vivendi: предприниматели и особенно самозанятые могут позволить себе более гибкие формы поведения, что же касается руководителей разного уровня, то они являются членами производственных структур и по определению имеют гораздо меньше возможностей (да и желания) демонстрировать свое пренебрежение устоявшимися нормами и правилами. С другой стороны, в этой группе самые маленькие вариации культурных показателей «Индивидуализм» и «Маскулинность», что свидетельствует о ключевой роли именно этих показателей в формировании в ней групповой идентичности.

Фиксируя диапазон показателя «Дистанция власти» в группе специалистов, сошлемся в его объяснении на вывод, сделанный О.И. Шкаратаном: «Мы имеем раскол в профессиональной среде, который сказывается как на мотивации, так и на трудовом поведении. < .. > Данные представительных опросов подтвердили предположение, что в современной России социальные слои профессионалов находятся в сложном положении, которое характеризуется невозможностью расширенного воспроизводства их человеческого капитала, социального статуса и обеспечения высокой инновационной активности» [Шкаратан, Инясевский 2006, с. 26-27].

При всей довольно большой неоднородности работающих в целом по показателю «Маскулинность» самый большой разброс этого признака наблюдается в ядре группы служащих и госслужащих. Видимо, это результат того, что в современной России чиновники рассматривают свою трудовую деятельность как совмещение ценностей «служения» с ценностями «карьеры», «заработка» и «престижа» (причем в среде молодежи превалируют как раз достижительные мотивации) [Бушуева, Богдан, Зубов 2014].

Наконец, по показателю «Индивидуализм» наибольший размах отмечается у работников торговли и бытовых услуг. Причиной такого явления может служить внутренняя неоднородность структурных позиций рядовых работников торговли, среди которых, например, представители сетевого маркетинга соседствуют с кассирами супермаркетов. При этом абсолютно во всех профессиональных группах работающих верхняя граница размаха показателя «Индивидуализм» составляет 105 баллов, а различия проявляются только в нижней границе (у работников торговли и бытовых услуг она составила -20 баллов). Интересно при этом, что в группе рабочих сильная вариация (в сравнении с другими профессиональными группами) показателей их производственной культуры вообще отсутствует. Это свидетельствует о том, что в данной группе ментальные программы у $66 \%$ полярных частей ее состава сконцентрированы в целом около средних величин - показателей Г. Хофстеда.

Итак, практически все группы трудящихся характеризуются в той или иной мере отсутствием концентрации культурных параметров около показателей Г. Хофстеда. Единственная категория, которая на фоне других групп трудящихся выглядит внутренне более цельной, - это рабочие. С точки зрения менеджмента, такая концентрация - позитивный фактор, поскольку свидетельствует о возможности применения по отношению к ним единых методов управления. Но есть у данного феномена и другая сторона медали: спектр подходящих моделей менеджмента, которые возможно применить к этой высоко сплоченной по своим нормативно-ценностным системам группе, весьма ограничен. 
Чтобы ответить на вопрос о наиболее эффективных в данной ситуации моделях, необходимо проанализировать культурные особенности рабочих на фоне других общностей, в том числе профессиональных. Чтобы получить, с одной стороны, более комплексное, а с другой, более точное представление о различиях между разными категориями работников по всем четырем показателям Хофстеда, обратимся к ментальной карте, построенной на основе многомерного шкалирования $^{9}$ (рисунок 1). Ключевая величина при данной процедуре - расстояние между точками: если две точки на изображении сильно удалены друг от друга, то между соответствующими объектами имеется значительное расхождение, и, наоборот, близость точек свидетельствует об их сходстве. Кроме разных категорий работников, на карте обозначено место России в целом (включая неработающее население), а также позиции ряда стран Востока и Запада по данным Г. Хофстеда ${ }^{10}$.

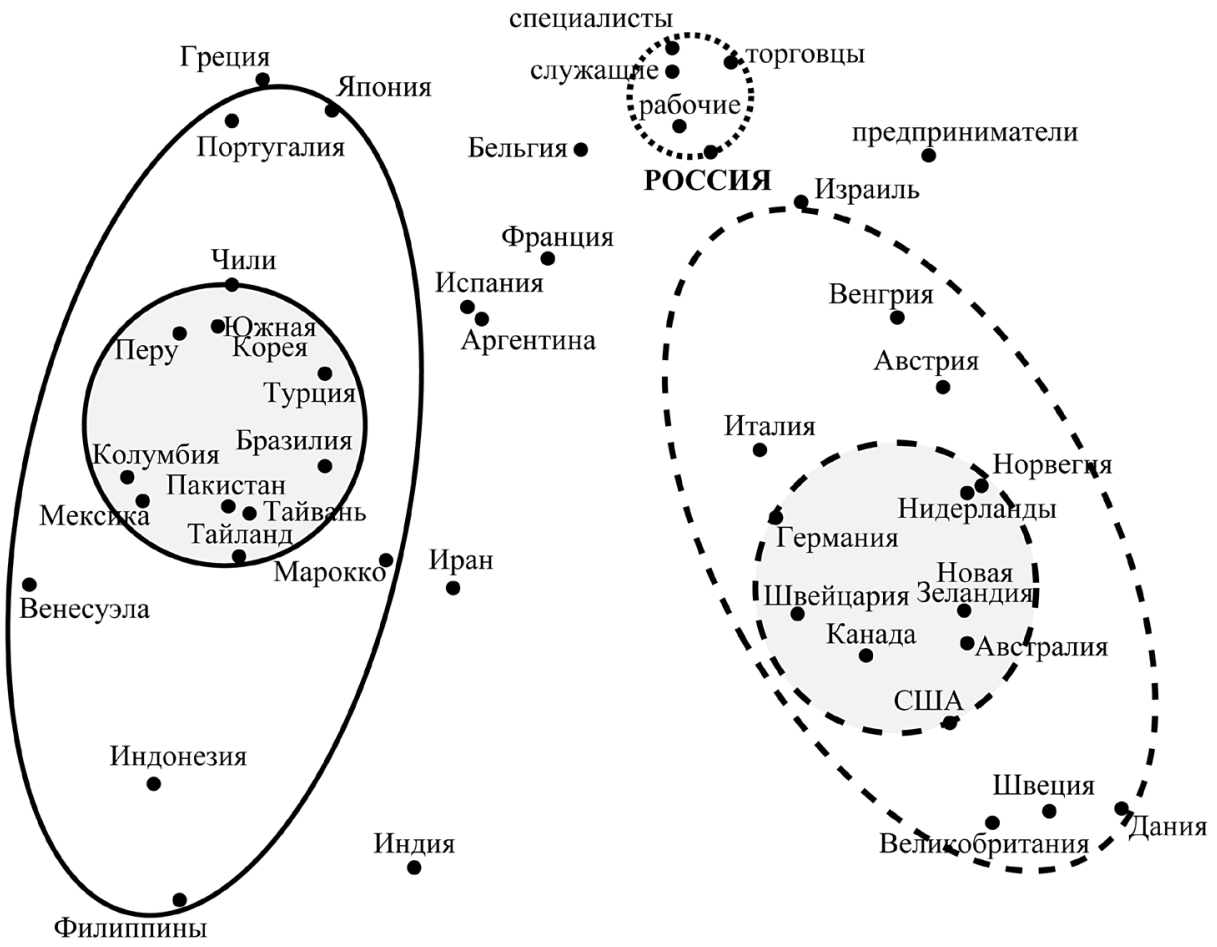

Рисунок 1. Результаты многомерного шкалирования (ALSCAL) различных групп российских работников и 62 стран, включая Россию

\footnotetext{
9 Процедура многомерного шкалирования применялась при помощи функции ALSCAL программного пакета SPSS. Параметры моделирования: Stress-value $=0,176$; RSQ $=0,848$.

10 Более подробно о месте России на ментальных картах мира см. [Латова, Тихонова 2010].

11 На рисунке 1 группы стран Востока и Запада обведены овалами, области концентрации стран (затемненные круги) представляют ядра этих групп. Для облегчения зрительного восприятия показаны только 38 зарубежных стран. Данные по зарубежным странам представлены по [Hofstede 2001, pp. 500, 502]
} 
Для начала посмотрим, как соотносятся между собой разные категории российских работников, обратив при этом особое внимание на рабочих. В данном случае важно понять, насколько производственная культура рабочих уникальна и представительна для культурных параметров россиян в целом. Как видно на рисунке 1, производственная культура рабочих как единая группа, с одной стороны, противостоит культурным особенностям предпринимателей, самозанятых и руководителей, a c другой, схожа с культурными отличительными чертами остальных категорий российских работников, хотя на фоне зарубежных стран различия между ними очень невелики, и все они находятся в своем особом, российском ареале. При этом дополнительный анализ ситуации с различными профессиональными группами в других странах показывает: если вести речь о двух диаметрально противоположных группах - рабочих, с одной стороны, и руководителях, с другой, - то в России проявляются те же тенденции, что и за рубежом, где рабочие больше ориентированы на наличие иерархии и в меньшей степени характеризуются наличием достижительных мотиваций. В то же время в России очень специфична категория специалистов, которые по своим культурным особенностям примыкают скорее к рабочим, чем к руководителям и предпринимателям, что не типично для большинства стран зарубежья. В итоге в современном российском обществе рабочие оказываются очень близки к «средней по стране» и могут с учетом их большей гомогенности в определенной степени даже служить культурно-нормативным лицом российского общества в целом. Отечественные предприниматели и руководители, наоборот, как бы выпадают из культурной ткани российского социума, что делает особенно актуальным вопрос об их способности руководить с учетом понимания ими специфики национальной культуры. По своему менталитету они тяготеют скорее к западному культурному ареалу, что совершенно не характерно для России в целом и для основных профессиональных групп российских работников в частности.

Чтобы лучше понимать содержание культурных показателей российских работников, сравним их с показателями Г. Хофстеда для стран обобщенных ареалов Востока и Запада (таблиияа 2).

Таблица 2. Показатели культурной специфики стран Запада и Востока

\begin{tabular}{|l|c|c|c|c|}
\hline Группа стран & $\begin{array}{c}\text { Дистанция власти } \\
\text { (PDI) }\end{array}$ & $\begin{array}{c}\text { Индивидуализм } \\
\text { (IDV) }\end{array}$ & $\begin{array}{c}\text { Маскулинность } \\
\text { (MAS) }\end{array}$ & $\begin{array}{c}\text { Избегание } \\
\text { неоределенности } \\
\text { (UAI) }\end{array}$ \\
\hline Запад & 32 & 74 & 50 & 53 \\
\hline Восток & 69 & 27 & 49 & 76 \\
\hline Россия & 28 & 61 & 36 & 91 \\
\hline
\end{tabular}

Данные таблищы 2 дают возможность точнее оценить особенности России на фоне двух основных культурных ареалов мира. Однако следует учитывать, что общие показатели по России могут быть дополнительно дифференцированы по отдельным профессиональным группам (таблица 1). Поэтому, используя сравни- 
тельный метод интерпретации культурных показателей и помня об общей российской специфике, рассмотрим теперь разные категории российских работников и определим вектор их тяготения к Востоку или Западу.

Анализ полученных данных в первую очередь показывает, что среди всех категорий работников особое место занимают предприниматели, самозанятые и руководители разных уровней. В этой группе по сравнению с остальными категориями работников выявлены самый низкий показатель «Дистанции власти» (PDI=9), самый высокий «Индивидуализм» (IDV=73), самая высокая «Маскулинность» $(\mathrm{MAS}=41)$ и самое низкое «Избегание неопределенности» (UAI=86). При этом первые два показателя («Дистанция власти» и «Индивидуализм») приближены к тем, которые характеризуют страны Запада, хотя два других не позволяют говорить об этой группе даже как о носителях норм и ценностей западной культуры.

Оставшиеся четыре группы (специалисты, служащие, работники торговли и сферы услуг, а также рабочие) образуют компактную группу и близки друг к другу по показателям Хофстеда. Тем не менее необходимо отметить, что культурные параметры работников торговли и сферы услуг имеют определенную специфику на фоне трех остальных категорий: у них наблюдается более низкая «Дистанция власти» $(\mathrm{PDI}=25)$, более высокий «Индивидуализм» $(\mathrm{IDV}=65)$, более высокая «Маскулинность» $(\mathrm{MAS}=40)$. Однако среди тяготеющих, как представляется на первый взгляд, к западным характеристикам работников торговли и бытовых услуг наблюдается крайне высокий показатель «Избегания неопределености» (UAI=101), не типичный даже для большинства стран Востока (средний показатель - UAI=76).

В свою очередь культурные особенности рабочих наиболее близки к тем параметрам, которые отличают население России в целом, т.е. низкая «Дистанция власти» $(\mathrm{PDI}=30)$, низкая «Маскулинность» $(\mathrm{MAS}=32)$ и высокое «Избегание неопределенности» (UAI=94), при этом показатель «Индивидуализм» у российских рабочих равен 59. Сравнение этого показателя со средними по группам стран Запада (IDV=74) и Востока (IDV=27) указывает на то, что российские рабочие далеки и от тех, и от других, но все же ближе к Западу: они точно не коллективисты, но и к классическим индивидуалистам их причислить также сложно. Скорее, речь может идти об их умеренном индивидуализме, предпочтении ориентироваться на личные нужды, и это характерно для населения России в целом. Таким образом, в своей совокупности эти отличия делают почти равноудаленными как от ядра культурной специфики стран Востока, так и от основных культурных параметров Запада и население нашей страны в целом, и российских рабочих в частности.

Более подробно представить себе особенности производственной культуры российских рабочих, являющиеся неотъемлемым элементом их человеческого капитала, позволяют ответы на вопросы о том, какой должна быть идеальная работа, т.е. как необходимо строить отношения на работе и какой производственный климат их устраивает в большей степени (таблиц̧а 3$)^{12}$.

\footnotetext{
12 В качестве определений идеальной работы в таблице 3 представлены смысловые интерпретации вопросов, фигурирующих в анкете Г. Хофстеда. Например, вопрос из анкеты «Насколько важно работать с людьми, которые умеют сотрудничать?» проинтерпретирован в таблице 3 как согласие с тем, что «важно, чтобы в коллективе были хорошие отношения, способствующие сотрудничеству». Более подробно о методике Г. Хофстеда см. [Латова (2) 2016; Латова 2003].
} 


\section{Таблица 3. Предпочтения российских рабочих относительно идеального места ра- боты, \% (ранжировано по совокупности ответов «полностью согласны» и «скорее согласны») ${ }^{13}$}

\begin{tabular}{|c|c|c|c|c|c|}
\hline 1 & 2 & 3 & 4 & 5 & 6 \\
\hline $\begin{array}{l}\text { Предпочтения относительно } \\
\text { идеального места работы }\end{array}$ & $\begin{array}{l}\text { Полностью } \\
\text { согласны }\end{array}$ & $\begin{array}{l}\text { Скорее } \\
\text { согласны }\end{array}$ & $\begin{array}{l}\text { Затруднились } \\
\text { определиться }\end{array}$ & $\begin{array}{l}\text { Скорее не } \\
\text { согласны }\end{array}$ & $\begin{array}{l}\text { Совершенно } \\
\text { не согласны }\end{array}$ \\
\hline \multirow{2}{*}{$\begin{array}{l}\text { Важно, чтобы в коллективе } \\
\text { были хорошие отношения, } \\
\text { способствующие сотрудничеству }\end{array}$} & 47 & 41 & \multirow{2}{*}{8} & 3 & 1 \\
\hline & \multicolumn{2}{|c|}{$88^{14}$} & & \multicolumn{2}{|c|}{4} \\
\hline \multirow{2}{*}{$\begin{array}{l}\text { Важно иметь хорошие } \\
\text { отношения с непосредственным } \\
\text { руководителем }\end{array}$} & 46 & 41 & \multirow{2}{*}{9} & 3 & 1 \\
\hline & \multicolumn{2}{|c|}{87} & & \multicolumn{2}{|r|}{4} \\
\hline \multirow{2}{*}{$\begin{array}{l}\text { Важно, чтобы работа } \\
\text { не подавляла личную жизнь }\end{array}$} & 42 & 39 & \multirow{2}{*}{9} & 8 & 2 \\
\hline & \multicolumn{2}{|c|}{81} & & \multicolumn{2}{|c|}{10} \\
\hline \multirow{2}{*}{$\begin{array}{l}\text { Работа должна давать } \\
\text { возможность } \\
\text { профессионального роста }\end{array}$} & 42 & 36 & \multirow{2}{*}{12} & 7 & 3 \\
\hline & \multicolumn{2}{|c|}{78} & & \multicolumn{2}{|c|}{10} \\
\hline \multirow{2}{*}{$\begin{array}{l}\text { Важно иметь четкую } \\
\text { иерархическую структуру } \\
\text { с одним начальником }\end{array}$} & 32 & 39 & \multirow{2}{*}{18} & 9 & 2 \\
\hline & \multicolumn{2}{|c|}{71} & & \multicolumn{2}{|c|}{11} \\
\hline \multirow[t]{2}{*}{$\begin{array}{l}\text { Важно, чтобы руководитель } \\
\text { советовался с подчиненными }\end{array}$} & 32 & 32 & \multirow{2}{*}{22} & 10 & 4 \\
\hline & \multicolumn{2}{|c|}{64} & & \multicolumn{2}{|c|}{14} \\
\hline \multirow{2}{*}{$\begin{array}{l}\text { Правила должны быть } \\
\text { обязательными } \\
\text { при любых обстоятельствах }\end{array}$} & 20 & 39 & \multirow{2}{*}{31} & 7 & 3 \\
\hline & \multicolumn{2}{|c|}{59} & & \multicolumn{2}{|c|}{10} \\
\hline \multirow{2}{*}{$\begin{array}{l}\text { Важно, чтобы между } \\
\text { работниками } \\
\text { не было конкуренции }\end{array}$} & 19 & 34 & \multirow{2}{*}{27} & 15 & 5 \\
\hline & \multicolumn{2}{|c|}{53} & & \multicolumn{2}{|c|}{20} \\
\hline \multirow{2}{*}{$\begin{array}{l}\text { Работа должна быть интересной, } \\
\text { не рутинной }\end{array}$} & 23 & 26 & \multirow{2}{*}{25} & 19 & 7 \\
\hline & \multicolumn{2}{|c|}{49} & & & 26 \\
\hline $\begin{array}{l}\text { На работе надо проявлять } \\
\text { самостоятельность, руководитель }\end{array}$ & 6 & 21 & & 28 & 17 \\
\hline $\begin{array}{l}\text { не может давать ответы } \\
\text { на все вопросы }\end{array}$ & 2 & & 20 & & 45 \\
\hline
\end{tabular}

13 Светло-серым тоном выделены ячейки с показателями, указывающими на доминирующие нормы и ожидания рабочих в производственной среде. Более темным фоном с белыми цифрами выделены ячейки с показателями, демонстрирующими нормы, разделяемые более чем $2 / 3$ рабочих.

14 В таблице 3 показаны данные, которые являются совокупностью ответов «полностью согласны» и «скорее согласны» (столбцы 2 и 3), а также «скорее не согласны» и «совершенно не согласны» (столбцы 5 и 6). 
Самое большое единодушие у российских рабочих вызывает необходимость хороших отношений в коллективе - как по горизонтали (среди коллег), так и по вертикали (с руководителем). С этим соглашается примерно 87-88\% всех рабочих, при этом 78-81\% ожидают, что работа должна давать определенную свободу для проявления своих индивидуальных способностей и интересов, причем как в профессиональной карьере, так и в личной жизни. Около 64-71\% в отношении руководителя предпочитают единовластие (наличие одного руководителя), но в то же время склонны ограничивать его властные полномочия элементами совещательности. Таким образом, вырисовывается следующая модель норм и ожиданий: производственный коллектив должен быть ориентирован на сотрудничество ради общей цели, а на не конкуренцию в борьбе за индивидуальный успех; хорошие отношения как между его членами, так и с руководством являются важнейшей предпосылкой мотивированности людей на эффективную работу; сама по себе работа и успех в ней - не самоцель, а скорее средство (в формировании чувства сопричастности в реализации общего дела, в самореализации, в профессиональном росте) и в качестве такового не может подчинять себе всю жизнь человека, а должна оставлять ему время на личную жизнь; руководитель в этой системе отвечает за все и должен давать ответы на все вопросы, но при этом быть не «гуру», а специалистом в своем деле, умеющим и посоветоваться с другими, и использовать «коллективный разум». Как видим, это непротиворечивая целостная система представлений о том, как должны строиться отношения на работе, способная при ее учете обеспечить очень высокую эффективность работников.

\section{Рабочая артель: прошлое и будущее российского эффективного менеджмента}

Разберемся более подробно с интерпретацией культурной специфики российских рабочих с точки зрения методов управления этой категорией работников. Высокий показатель «Избегание неопределенности» свидетельствует о том, что эффективная деятельность рабочих возможна только при наличии четких правил и при минимизации индивидуальных рисков. Низкий показатель «Маскулинности» сигнализирует о важности взаимоотношений в коллективе, приоритете поддержания благоприятного производственного климата в противовес достижению результата любой ценой. Средний показатель «Индивидуализм» характеризует важность наличия связи результатов труда с личными достижениями конкретного работника. При этом важно отметить, что оценка личных достижений не должна оказывать влияние на взаимоотношения работников внутри коллектива (т.е. «Индивидуализм» не должен противоречить «Маскулинности»).

C учетом вышесказанного введение механизмов конкуренции между российскими работниками внутри коллектива не будет давать столь положительного эффекта, как в западных странах с высокими показателями «Индивидуализма» и «Маскулинности»: более вероятно, что ориентация на поддержание благоприятных взаимоотношений возобладает и нивелирует стремление проявить индивидуальные способности. Тем не менее использовать конкурентные начала можно и в России, но организуя скорее коллективные, чем индивидуальные формы соревно- 
вания. В рамках такой конкуренции личные достижения отдельных работников будут рассматриваться коллективом как стремление к общему благу.

Наконец, низкий показатель «Дистанция власти» требует наличия доступного и равноправного руководителя: по сути, начальником должен быть наиболее знающий, авторитетный и уважаемый всеми член того же коллектива, взаимоотношения с которым подразумевают высокую степень неформальности («первый среди равных»).

Если перечисленные параметры производственной культуры являются отличительными особенностями российской культуры в целом, то следовало бы ожидать, что ее историческое развитие уже продемонстрировало специфические формы организации труда, обусловленные этими характеристиками. Действительно, в реальности новое оказывается хорошо забытым старым. Описание стратегии управления рабочими на основе культурных показателей Г. Хофстеда заставляет вспомнить о рабочих артелях - исторически сформировавшемся в дореволюционной России принципе организации труда. Они возникали во множестве профессиональных видов занятий (строительство, рыболовный промысел, работа грузчиков, бурлаков и т.д.), где требовался слаженный коллективный труд под единым руководством. Если в Западной Европе трудовая кооперация развивалась главным образом в рамках системы капиталистического индивидуального найма, то в России развитие пошло иначе.

Пристальное внимание экономистов-народников к этой форме трудовой организации было связано именно с тем, что в ней они видели один из элементов спонтанно развивающегося «народного производства», которое преодолевает застойность сельского образа жизни, но не за счет капиталистической «погони за наживой». Благодаря исследователям второй половины XIX в. современным ученым доступен обширный описательный материал, характеризующий специфику российских артелей [Калачев 1864; Энгельгардт 2010; Исаев 1881; Щербина 1881; Воронцов 1895]. Действительно, определение артели как объединения, «создаваемого для совместной деятельности на началах самоуправления, солидарности и взаимной ответственности» [Аверьянов 2014, с. 107], вполне соответствует описанным выше культурным особенностям современных российских рабочих. Важный элемент понимания функционирования артелей - это несводимость к чисто экономическим началам и принципам. «Капиталистического духа» в артелях, т.е. стремления получить максимальную материальную выгоду, было явно мало: они представляли собой не просто механическое объединение людей, но являлись своего рода общественной организацией, смысл которой - удовлетворить «разнообразные жизненные потребности личности - духовные, правовые, политические и экономические» [Слобожанин 1919, с. 75], и основывались на равноправии, справедливом вознаграждении, взаимопомощи и взаимовыручке [Платонов 1991, с. 55-56].

Если сравнивать полученные нами характеристики производственной культуры рабочих и те характеристики русской трудовой артели, которые считались для нее нормативными, то мы увидим высокую степень согласованности между ними (таблица 4).

Артельный тип организации труда типичен не только для дореволюционной России. Точно так же можно охарактеризовать и различные методы бригадной организации труда в СССР вплоть до 1980-х гг., причем чем менее официальными были эти бригады (например, бригады шабашников), тем сильнее они напоминали традиционные артели. 
Таблица 4. Взаимосвязь современных характеристик производственной культуры рабочих и характеристик русской трудовой артели

\begin{tabular}{|c|c|c|}
\hline $\begin{array}{l}\text { Степень выраженности } \\
\text { культурных характери- } \\
\text { стик рабочих }\end{array}$ & $\begin{array}{l}\text { Вытекающие } \\
\text { требования к } \\
\text { организации труда }\end{array}$ & Характеристики русской трудовой артели* \\
\hline $\begin{array}{l}\text { Низкая } \\
\text { «Дистанция власти» }\end{array}$ & $\begin{array}{l}\text { Наличие равного } \\
\text { другим («первого } \\
\text { среди равных») } \\
\text { доступного } \\
\text { и готового к } \\
\text { консультациям с } \\
\text { членами коллектива } \\
\text { руководителя }\end{array}$ & $\begin{array}{l}\text { «Начало равенства не нарушается предоставлением } \\
\text { одному из членов исполнительной власти во внутренних } \\
\text { отношениях артели <..>, ибо каждый из членов } \\
\text { может стоять во главе исполнительной власти, а в } \\
\text { иных артелях право это переходит в обязанность, } \\
\text { ложащуюся поочередно на всех артельщиков. } \\
\text { Началом равноправности артель резко отличается от } \\
\text { капиталистических форм предприятий». }\end{array}$ \\
\hline $\begin{array}{l}\text { Средний } \\
\text { «Индивидуализм» }\end{array}$ & $\begin{array}{l}\text { Связь результатов } \\
\text { труда с личными } \\
\text { достижениями } \\
\text { работника }\end{array}$ & $\begin{array}{l}\text { «Лица, являющиеся полноправными членами артели, } \\
\text { равноправны между собой. }<. .>\text { Равенство это }<\ldots . .> \\
\text { не нарушается встречающимся часто на практике } \\
\text { не абсолютно равным разделом общей прибыли, } \\
\text { поступающей в большем размере собственнику капитала } \\
\text { или орудий производства или лицу, руководящему } \\
\text { артелью, так как этот излишек является вознаграждением } \\
\text { за капитал, труд или технические познания и } \\
\text { опытность». }\end{array}$ \\
\hline $\begin{array}{l}\text { Низкая } \\
\text { «Маскулинность» }\end{array}$ & $\begin{array}{l}\text { Приоритет } \\
\text { поддержания } \\
\text { отношений в } \\
\text { противовес } \\
\text { достижению } \\
\text { результата любой } \\
\text { ценой }\end{array}$ & $\begin{array}{l}\text { «Члены артели связаны круговою порукой, т.е. } \\
\text { каждый из них ручается солидарно за всех остальных. } \\
<\ldots . \text { Э Эта ответственность друг за друга есть искони } \\
\text { отличительный признак артелей». }\end{array}$ \\
\hline $\begin{array}{l}\text { Высокое } \\
\text { «Избегание } \\
\text { неопределенности» }\end{array}$ & $\begin{array}{l}\text { Наличие четких } \\
\text { правил, реализацию } \\
\text { которых обеспечивает } \\
\text { руководитель, } \\
\text { выступающий } \\
\text { не только в роли } \\
\text { организатора, но и } \\
\text { арбитра }\end{array}$ & $\begin{array}{l}\text { «Артель есть союз, основанный на договоре. }<\ldots . . \\
\text { Этот договор ясно выступает наружу в письменном } \\
\text { акте в более развитых формах артели, в других } \\
\text { ограничивается словесным соглашением }<\ldots>\text {, а иногда } \\
\text { вовсе не проявляется вовне, являясь лишь молчаливым } \\
\text { договором, возможность которого обусловливается } \\
\text { общеизвестностью обычая, регулирующего строй этих } \\
\text { союзов». }\end{array}$ \\
\hline
\end{tabular}

* [Артель 1890, с. 184-194].

В целом и русские артели, и советские бригады демонстрировали форму организации трудовой деятельности, основные принципы которой с точки зрения современных стратегий менеджмента можно сформулировать следующим образом:

- самоуправление;

- согласованность действий при выполнении работ с вознаграждением по личному вкладу;

- общая ответственность;

- четкие внутренние (зачастую неформальные) трудовые правила.

Итак, можно констатировать, что производственная культура рабочих хорошо сочетается с исконно российской высокоэффективной хозяйственной организацией в форме артелей. Этот принцип организации труда позволяет использовать сильные стороны производственной культуры российских рабочих и одновременно с этим проясняет низкую эффективность в российских условиях заимствования 
иностранных стратегий менеджмента. Имплантация подобных методов, очевидно, вполне возможна, но речь должна идти в первую очередь о тех, в которых есть определенные аналогии российским артелям/бригадам. Действительно, в странах Западной Европы чем-то схожим являются, например, появившиеся еще в XIX в. кооперативные предприятия, на Востоке - сложившиеся во второй половине XX в. японские системы кружков качества и пожизненного найма.

\section{Можно ли выйти из матрицы?}

Зададимся вопросом, как происходит ментальное программирование человека и есть ли основания полагать, что коридор возможностей для получения эффективного производственного результата детерминирован не только стратегиями менеджмента, но допускает и другие механизмы достижения поставленных целей. В случае если культурные особенности являются достаточно эластичной (легко меняющейся) характеристикой человеческого капитала, то можно было бы не подбирать «под работников» результативную стратегию менеджмента, а, наоборот, подстраивать установки и нормы работников под существующие на Западе или на Востоке схемы эффективного управления. Так как основная форма инвестиций в человеческий капитал - это инвестиции в образование, то для исследования процессов ментального программирования необходимо рассмотреть роль образования в формировании культурной специфики российских работников вообще и рабочих в частности.

Разделим данную задачу на две подзадачи: первая - изучение влияния социального происхождения (образование родителей) на культурные характеристики работников; вторая - анализ влияния на них же условий образовательной социализации самих работников (их собственное образование). Далее следует выяснить, есть ли какая-нибудь взаимосвязь между уровнем образования родителей, профессиональным статусом их детей и их культурными отличиями. Для начала определимся, есть ли какая-то зависимость профессиональной принадлежности респондентов от их социального происхождения ${ }^{15}$.

Данные в таблище 5 свидетельствуют о том, что в большинстве случаев (56\%) статус семьи как «низкообразованной» был связан с приобретением детьми из этой среды рабочей профессии, семьи с высокообразованными родителями в $49 \%$ случаев определяли профессиональный статус своих детей как специалистов, а семьи со средним образованием продуцировали $36 \%$ рабочих и $26 \%$ специалистов. Таким образом, мы можем говорить о наследовании социальных статусов и социальном воспроизводстве этой группы, в том числе и культурном (особенно применительно к рабочим).

\footnotetext{
15 При анализе образовательного уровня семей применялось агрегирование в группы, где статус семьи определялся положением родителей по уровню их образования. В том случае, если оба родителя (если семья неполная профессиональный статус фиксировался по единственному родителю) имели образование не выше общего среднего, то статус семьи квалифицировался как низкообразованная семья; семьи с родителями, имеющими высшее образование, - как высокообразованные; наконец, во всех остальных случаях (родители имели среднее специальное, незаконченное высшее образование, а также различные сочетания высшего образования у одного из родителей с более низкими уровнями образования у другого) семьи идентифицировались как имеющие статус среднеобразованных.
} 
Таблица 5. Профессиональный статус работающих россиян в зависимости от образовательного уровня их родительской семьи, \%

\begin{tabular}{|l|c|c|c|}
\hline \multirow{2}{*}{$\begin{array}{l}\text { Профессиональный статус } \\
\text { респондентов }\end{array}$} & \multicolumn{3}{|c|}{$\begin{array}{c}\text { Статус семьи респондентов } \\
\text { повнобразования их родителей }\end{array}$} \\
\cline { 2 - 4 } & Низкообразованные & Среднеобразованные & Высокообразованные \\
\hline $\begin{array}{l}\text { Предприниматели, самозанятые } \\
\text { и руководители разного уровня }\end{array}$ & 9 & 9 & 13 \\
\hline Специалисты & 11 & 26 & 49 \\
\hline Служащие & 10 & 14 & 11 \\
\hline $\begin{array}{l}\text { Работники торговли и сферы } \\
\text { услуг }\end{array}$ & 14 & 15 & 14 \\
\hline Рабочие & 56 & 36 & 13 \\
\hline
\end{tabular}

Чтобы определить, как образовательный статус семьи влияет на культурные характеристики их детей, проанализируем показатели Г. Хофстеда в трех выделенных нами образовательных подгруппах (таблиц̧а 6).

Таблица 6. Культурные показатели респондентов в зависимости от образовательного статуса семьи, \%

\begin{tabular}{|l|c|c|c|c|}
\hline $\begin{array}{l}\text { Статус семьи по уровню } \\
\text { образования родителей }\end{array}$ & $\begin{array}{c}\text { «Дистанция } \\
\text { власти» } \\
\text { (PDI) }\end{array}$ & $\begin{array}{c}\text { «Индивидуализм» } \\
\text { (IDV) }\end{array}$ & $\begin{array}{c}\text { «Мскулинность» } \\
\text { (MAS) }\end{array}$ & $\begin{array}{c}\text { неопределанине } \\
\text { (UAI) }\end{array}$ \\
\hline $\begin{array}{l}\text { Низкообразованные } \\
\text { (N=810) }\end{array}$ & 27 & 57 & 32 & 85 \\
\hline $\begin{array}{l}\text { Среднеобразованные } \\
\text { (N=702) }\end{array}$ & 28 & 63 & 37 & 105 \\
\hline $\begin{array}{l}\text { Высокообразованные } \\
\text { (N=163) }\end{array}$ & 30 & 68 & 48 & 96 \\
\hline
\end{tabular}

Полученные показатели демонстрируют картину различий культурных характеристик выходцев из семей с разным образовательным уровнем. Прослеживается следующая закономерность: повышение уровня образования родительской семьи влечет за собой и повышение всех показателей Хофстеда выросшего в ней человека: чем выше статус семьи по образовательному уровню родителей, тем сильнее у респондентов выражены «Дистанция власти», «Индивидуализм», «Маскулинность» и «Избегание неопределенности». Если же акцентировать внимание на семьях, которые продуцируют в основном рабочих (семьи со статусом «низкообразованные»), то выходцы из таких семей в сравнении со всеми остальными россиянами имеют чуть более низкую «Дистанцию власти» и заметно более 
низкие «Индивидуализм», «Маскулинность» и «Избегание неопределенности». Семьи среднеобразованных родителей, которые также играют важную роль в формировании категории рабочих, по своим культурным показателям находятся между низкообразованными и высокообразованными семьями.

Таким образом, если говорить о том, как влияет уровень образованности родительской семьи на тяготение культурных параметров россиян к цивилизациям Запада или Востока, то можно зафиксировать следующие закономерности: выходцы из высокообразованных семей выглядят немного более прозападными (заметно более высокий «Индивидуализм» и «Маскулинность», чем у представителей остальных типов семей), чем выходцы из семей с низким уровнем образования родителей. В то же время однозначно определить культурные характеристики выходцев из низкообразованных семей как провосточные тоже не представляется возможным. Это в очередной раз подтверждает наш тезис о том, что западные стратегии менеджмента с высокой долей вероятности не найдут отклика у современных российских рабочих (впрочем, как и чисто восточные).

Перейдем ко второй части анализа ментального программирования россиян к пониманию влияния образовательной социализации на профессиональное самоопределение респондентов и их культурные особенности. Привязка образования ${ }^{16}$ к личному профессиональному статусу в современной российской действительности прослеживается весьма легко (таблица 7): низкообразованные россияне, как правило, являются рабочими (76\%), высокообразованные составляют костяк специалистов (69\%), а среднеобразованные трудятся либо в качестве рабочих (50\%), либо как рядовые работники торговли и сферы услуг (21\%).

\section{Таблица 7. Распределение категорий работников в зависимости от их личного образо- вательного уровня, \%}

\begin{tabular}{|l|c|c|c|}
\hline \multirow{2}{*}{$\begin{array}{l}\text { Профессиональный статус } \\
\text { респондентов }\end{array}$} & \multicolumn{3}{|c|}{ Статус респондентов по уровно их личного образования } \\
\cline { 2 - 4 } $\begin{array}{l}\text { Предприниматели, самозанятые } \\
\text { и руководители разного уровня }\end{array}$ & 5 & 7 & 18 \\
\hline Специалисты & 0 & 4 & 69 \\
\hline Служащие & 3 & 18 & 9 \\
\hline $\begin{array}{l}\text { Работники торговли } \\
\text { и сферы услуг }\end{array}$ & 16 & 21 & 1 \\
\hline Рабочие & 76 & 50 & 3 \\
\hline
\end{tabular}

16 Для определения статуса респондентов по уровню их личного образования применялась та же классификация, что и в случае установления образовательного уровня их родителей: образование не выше общего среднего формировало группу низкообразованных россиян, любые формы высшего образования давали респондентам статус высокообразованных, а среднее специальное и незаконченное высшее образование приписывало респондента к группе среднеобразованных. 
Хотя связь личного образования с профессиональным статусом несомненна, как и связь последнего с уровнем образованности родительской семьи, однако найти зависимость личного образования и культурных показателей Г. Хофстеда оказалось затруднительным (таблица 8). Из этого следует сделать вывод, что, вероятно, личное образование не оказывает какого-либо добавочного (по сравнению с образованием родителей) существенного влияния на культурные характеристики, которые закладываются еще во время первичной социализации.

\section{Таблица 8. Культурные показатели респондентов в зависимости от их собственного образовательного статуса, \%}

\begin{tabular}{|l|c|c|c|c|}
\hline $\begin{array}{l}\text { Статус россиян } \\
\text { по уровно образования }\end{array}$ & $\begin{array}{c}\text { «Дистанция } \\
\text { власти» } \\
\text { (PDI) }\end{array}$ & $\begin{array}{c}\text { «Индивидуализм» } \\
\text { (IDV) }\end{array}$ & $\begin{array}{c}\text { «Макулинность» } \\
\text { (MAS) }\end{array}$ & $\begin{array}{c}\text { «Избегание } \\
\text { непеденности» } \\
\text { (UAI) }\end{array}$ \\
\hline $\begin{array}{l}\text { Низкообразованные } \\
\text { (N=469) }\end{array}$ & 22 & 61 & 46 & 81 \\
\hline $\begin{array}{l}\text { Среднеобразованные } \\
\text { (N=764) }\end{array}$ & 32 & 60 & 30 & 94 \\
\hline $\begin{array}{l}\text { Высокообразованные } \\
\text { (N=462) }\end{array}$ & 25 & 64 & 34 & 97 \\
\hline
\end{tabular}

Итак, изучение влияния образования на культурные особенности россиян привело нас к выводу о ключевой роли социального происхождения в ментальном программировании ${ }^{17}$. Однако надо иметь в виду, что по мере развития общества растет и средняя образованность его граждан. Если раньше низкообразованная семья не воспринималась как некая аномалия, то в последнее время наблюдается явный сдвиг в сторону того, чтобы семейной нормой стало хотя бы среднее специальное образование. Таким образом, можно предположить, что культурные отличия рабочих по мере повышения средней образованности общества будут изменяться в сторону повышения всех показателей, особенно «Избегания неопределенности» и «Индивидуализма», т.е. их общий вектор будет сдвигаться в сторону прозападных культурных ценностей, но все же с сохранением российской специфики.

Может ли это служить основой для сомнений в эффективности артельного метода организации рабочего труда в перспективе, или культурные особенности рабочих как профессиональной группы более стойки? Для ответа на этот вопрос проанализируем, каким образом меняется культурное своеобразие с возрастом. Чтобы максимально исключить влияние возраста на готовность к инвестициям (у молодых людей по сравнению с пожилыми выше готовность инвестировать в новые умения, навыки и способности, поскольку у них больше лет жизни, чтобы окупить эти вложения), ограничим максимальный возраст респондентов 40 годами (это возраст, когда еще не сказывается эффект ослабления стимулов к инвестированию

17 Следует сделать оговорку, что выявленные корреляции, строго говоря, не являются основанием для жестких каузальных выводов; данный вопрос в дальнейшем требует более глубокого анализа. 
в человеческий капитал) и выделим две подгруппы: молодежь (18-30 лет) и люди среднего возраста (31-40 лет). Такое деление непосредственно связывает возраст с производственной деятельностью: до 30 лет включительно только $37 \%$ респондентов получили повышение в должности, а остальные $63 \%$ - лишь в 31-60 лет, причем 29\% всех повышений приходится на период с 31 года до 40 лет.

Полученные данные (таблица 9) демонстрируют наличие определенных сдвигов в культурных особенностях в зависимости от возраста респондентов: в группе 31-40-летних наблюдается повышение показателей «Дистанция власти» и «Избегание неопределенности» с одновременным понижением «Индивидуализма» и «Маскулинности». При этом культурная специфика людей среднего возраста практически полностью повторяет культурные показатели работающих россиян в целом (таблица 1). Это позволяет предположить, что именно в среднем возрасте происходит прочное встраивание в систему российской производственной культуры.

\section{Таблица 9. Культурные показатели респондентов в зависимости от их возраста, \%}

\begin{tabular}{|l|c|c|c|c|}
\hline Возраст россиян & $\begin{array}{c}\text { «Дистанция } \\
\text { власти» } \\
\text { (PDI) }\end{array}$ & $\begin{array}{c}\text { «Идивидуализм» } \\
\text { (IDV) }\end{array}$ & $\begin{array}{c}\text { «Масулинность» } \\
\text { (MAS) }\end{array}$ & $\begin{array}{c}\text { «еозбегание } \\
\text { (UAI) }\end{array}$ \\
\hline Молодежь (N=435) & 24 & 68 & 50 & 89 \\
\hline $\begin{array}{l}\text { Люди среднего возраста } \\
\text { (N=367) }\end{array}$ & 28 & 62 & 38 & 96 \\
\hline
\end{tabular}

Возвращаясь к производственной культуре рабочих, определим, каким образом взаимодействуют социальное происхождение и возраст (вторичная социализация при встраивании в профессию) у данной категории работников. Нам необходимо понять те тенденции, которые могут проявиться в том случае, если социальное происхождение рабочих изменится (т.е. какую роль может сыграть постепенное повышение уровня образования родителей у будущих рабочих). До сих пор мы рассматривали культурные особенности рабочих в зависимости от их социального происхождения и возраста, анализируя эти факторы по отдельности. Теперь изучим, какие изменения происходят в производственной культуре рабочих, если совокупно взять их возраст и социальное происхождение (таблища 10), т.е. рассмотреть кумулятивный эффект этих факторов.

Среди рабочей молодежи мы видим довольно существенные различия в культурных показателях в зависимости от их социального происхождения. Причем те тенденции, которые были выделены нами ранее среди всех россиян (абсолютно все культурные показатели детей из среднеобразованных семей выше, чем те же показатели у выходцев из семей с низким уровнем образования), среди рабочих выражены сильнее. Однако у рабочих среднего возраста роль социального происхождения заметно снижается (культурные показатели различаются в минимальной степени), а культурные показатели сопоставимы с теми, которые были получены нами по всей совокупности рабочих. 
Таблица 10. Культурные показатели рабочих в зависимости от их возраста и социального происхождения, \%

\begin{tabular}{|c|c|c|c|c|c|}
\hline Возраст & $\begin{array}{l}\text { Статус семьи } \\
\text { по уровню образо- } \\
\text { вания родителей }\end{array}$ & $\begin{array}{l}\text { «Дистанция } \\
\text { власти» } \\
\text { (PDI) }\end{array}$ & $\begin{array}{l}\text { «Индивидуа- } \\
\text { лизм» (IDV) }\end{array}$ & $\begin{array}{c}\text { «Маскулин- } \\
\text { ность» (MAS) }\end{array}$ & $\begin{array}{l}\text { «Избегание } \\
\text { неопределен- } \\
\text { ности» (UAI) }\end{array}$ \\
\hline \multirow{2}{*}{$\begin{array}{l}\text { Молодежь } \\
(\mathrm{N}=145)\end{array}$} & $\begin{array}{l}\text { Низкообразованные } \\
(\mathrm{N}=62)\end{array}$ & 13 & 69 & 43 & 82 \\
\hline & $\begin{array}{l}\text { Среднеобразованные } \\
(\mathrm{N}=83)\end{array}$ & 36 & 75 & 52 & 94 \\
\hline \multirow{2}{*}{$\begin{array}{l}\text { Люди } \\
\text { среднего } \\
\text { возраста } \\
(\mathrm{N}=139)\end{array}$} & $\begin{array}{l}\text { Низкообразованные } \\
\text { (N=72) }\end{array}$ & 32 & 52 & 36 & 99 \\
\hline & $\begin{array}{l}\text { Среднеобразованные } \\
\text { (N=67) }\end{array}$ & 28 & 56 & 35 & 92 \\
\hline \multicolumn{2}{|c|}{ Все рабочие $(\mathrm{N}=550)$} & 30 & 59 & 32 & 94 \\
\hline
\end{tabular}

На наш взгляд, это неоспоримое свидетельство того, что происходит воспроизводство нормативно-культурных особенностей рабочей профессиональной среды (к 40 годам стаж трудовой деятельности рабочих должен в среднем составлять порядка 20 лет). Независимо от роста уровня образования россиян, при таких результатах надо признать малую степень вероятности изменения культурных отличий российских рабочих в ближайшее время и очень высокую степень их устойчивости (о чем свидетельствовала и высокая концентрированность показателей Г. Хофстеда у рабочих, о которой говорилось выше). Следовательно, коридор возможностей реформирования российской экономики в части используемых в ней моделей менеджмента определяется перспективами эффективного использования того человеческого капитала, которым уже обладают российские рабочие. Учитывая их нормативно-культурные особенности и запрос на определенную модель организации производственных отношений, надежды на автоматическое расширение этого коридора со сменой поколений работников вряд ли основательны.

\section{Заключение}

Этнометрический анализ культурных особенностей россиян показал, что в целом наша нация достаточно гомогенна. Это проявляется как при сравнении концентрации (размаха) культурных отличий у представителей отдельных профессиональных групп, так и при сравнении культурных показателей четырех основных групп наемных работников в целом. Можно утверждать, что определенный разброс по отдельным показателям в группах работников не создает центробежного эффекта; все четыре основные профессиональные группы достаточно однородны и достаточно близки между собой. Этому единому блоку в определенной мере противостоит группа предпринимателей, самозанятых и руководителей, культурные установки которых гораздо ближе к западному менталитету (ментальным 
программам), хотя их культурную специфику также нельзя квалифицировать как исконно западную. Однако именно их культурные характеристики находятся вне культурной ткани остальной нации, пребывая в другом нормативно-культурном пространстве. В результате те реформаторские идеи и предложения, которые возникают в этой среде, рождаются во многом от непонимания того, как мыслит основная часть граждан, и не находят поддержки в широких слоях населения.

Культурная специфика российских рабочих на уровне общих закономерностей перекликается со спецификой рабочих в зарубежных странах: рабочие больше, чем предприниматели и руководители, ориентированы на наличие иерархии и в меньшей степени обладают достижительными мотивациями. Но в России это принимает несколько гипертрофированные формы, потому что исполнительский (неавтономный, отчужденный) характер труда достигает в определенном смысле апофеоза, будучи присущим большинству специалистов. Поэтому можно утверждать, что культурные особенности рабочих наиболее близки к тем, которыми характеризуется население России в целом. Принципиально важно при этом, что по своей совокупности все они делают почти равноудаленными как от ядра культурного своеобразия стран Востока, так и от ядра культурных характеристик Запада и население нашей страны в целом, и российских рабочих в частности.

Производственная культура российских рабочих, отражающаяся в культурных показателях Г. Хофстеда, - не что иное, как принципы рабочей артели. Эта форма трудовой организации была широко распространена в Российской империи; в советский период она также продолжала успешно развиваться, хотя и в модифицированном виде. Что же касается постсоветской России, то требуется дополнительное изучение вопроса о воспроизводстве этой формы организации труда. Если предположить, что в настоящее время она развита незначительно, то это может служить одним из объяснений демонстрации низкой эффективности труда российских рабочих: им сложно работать в рамках тех организационных форм, к которым «не лежит душа».

Следует подчеркнуть, что евразийский путь развития российской производственной культуры имеет вполне реальные перспективы, поскольку, судя по полученным данным, она остается стабильной даже в нынешних условиях, и, следовательно, легче и продуктивнее не ломать устоявшиеся формы трудовой деятельности, а использовать то, что уже есть и имеет давние традиции. Заметим, что традиционные российские формы менеджмента - это достаточно эффективная модель, и необходимо использовать ее сильные стороны, а они, безусловно, есть. Если мы сумеем применить исторический опыт этой культуры, отказавшись от слепого копирования как западных, так и восточных практик, то можно ожидать более эффективную работу и гораздо большую отдачу от человеческого капитала трудящихся вообще и рабочих в частности. С другой стороны, если продолжать калькировать западные образцы, рассчитанные на другую нормативно-культурную среду, то в итоге мы рискуем оказаться в ситуации басенного трио - лебедя, рака и щуки.

\section{Литература}

Аверьянов В. (2014) Русская артель. Невостребованный опыт: из прошлого в будущее? // Свободная мысль. № 3. С. 107-124. 
Артель (1890) // Энциклопедический словарь Брокгауза и Ефрона. Т. ІІ. СПб.: Семеновская Типолитография (И.А. Ефрона). С. 184-194.

Беккер Г. (2003) Человеческое поведение: экономический подход. Избранные труды по экономической теории. М.: ВШЭ.

Бушуева И.П., Богдан Н.Н., Зубов В.Е. (2014) Карьера в государственной гражданской службе: прошлое, настоящее, будущее // Управленческое консультирование. № 7(67). С. 7-18.

Воронцов В.П. (1895) Артельные начинания русского общества. СПб.: Типография И.Н. Скороходова.

Данилова Е., Тарарухина М. (2003) Российская производственная культура в параметрах Г. Хофштеда // Мониторинг общественного мнения. № 3 (65). С. 53-64.

Грачев М.В. (1999) Менеджмент в «международной системе координат» // Экономические стратегии. № 2. С. 19-31.

Инглхарт Р. (2002) Культура и демократия // Харрисон Л., Хантингтон С. (ред.) Культура имеет значение. Каким образом ценности способствуют общественному прогрессу. М.: Московская школа политических исследований. С. 106-128.

Инглхарт Р., Вельцель К. (2011) Модернизация, культурные изменения и демократия. Последовательность человеческого развития. М.: Новое издательство.

Исаев А. (1881) Артели в России. Ярославль: Печатня Губернского правления.

Калачев Н. (1864) Артели в древней и нынешней России. СПб.: Типография В. Головина.

Лаборатория сравнительных социальных исследований // Национальный исследовательский университет «Высшая школа экономики» // http://lcsr.hse.ru

Латова Н.В. (1) (2016) Влияние кризиса на удовлетворенность россиян своей жизнью и их социально-психологическое самочувствие // Горшков М.К., Тихонова Н.Е. (ред.) Российское общество и вызовы времени. Книга третья. М.: Весь Мир. С. 41-65.

Латова Н.В. (2) (2016) Культурная специфика россиян (этнометрический анализ на основе концепции Г. Хофстеда) // Вестник Института социологии. № 4 (19). С. 155-179.

Латова Н.В. (2003) Этнометрические измерения: теория и практика // Социология: методология, методы, математическое моделирование. № 17. С. 142-166.

Латова Н.В., Латов Ю.В. (2001) Российская экономическая ментальность на мировом фоне // Общественные науки и современность. № 4. С. 31-43.

Латова Н.В., Тихонова Н.Е. (2010) Модернизация и характеристики российской национальной ментальности // Горшков М.К., Крумм Р., Тихонова Н.Е. (ред.) Готово ли российское общество к модернизации? М.: Весь мир. С. 273-297.

Лебедева Н.М., Татарко А.Н. (2007) Ценности культуры и развитие общества. М.: ВШЭ.

Магун В.С., Руднев М.Г. (2010) Базовые ценности россиян и других европейцев (по материалам опросов 2008 года) // Вопросы экономики. № 12. С. 107-130.

Магун В.С., Руднев М.Г., Шмидт П. (2015) Европейская ценностная типология и базовые ценности россиян // Вестник общественного мнения. Данные. Анализ. Дискуссии. Т. 121. № 3-4. С. 74-93.

Платонов О.А. (1991) Русский труд. М.: Современник.

Сведения о заработной плате работников организаций по категориям персонала и профессиональным группам работников за октябрь 2015 г. (статистический бюллетень) (2016) // Федеральная служба государственной статистики // http://www.gks.ru/wps/wcm/connect/rosstat_main/rosstat/ru/statistics/wages/labour_costs

Слобожанин М. (1919) Новые построения в идеологии и теории кооператизма-артельности. Петроград.: Типография Петроградского союза потребительских обществ.

Харрисон Л., Хантингтон С. (ред.) (2002) Культура имеет значение. Каким образом ценности способствуют общественному прогрессу. М.: Московская школа политических исследований.

Хофстеде Г. (2014) Модель Хофстеде в контексте: параметры количественной характеристики культур // Язык, коммуникация и социальная среда. № 12. С. 9-49.

Цой Г., Лебедева Н.М., Татарко А.Н. (2016) Взаимосвязь ценностей и социально-экономических представлений у корейских и российских студентов // Психология. Журнал Высшей школы экономики. Т. 13. № 2. С. 310-322.

Шкаратан О.И., Инясевский С.А. (2006) Социально-экономическое положение профессионалов и менеджеров // Социологические исследования. № 10. С. 16-27. 
Щербина Ф. (1881) Очерки южно-русских артелей и общинно-артельных форм. Одесса: Типография Г. Ульриха.

Энгельгардт А. (2010) Письма из деревни. М.: Алгоритм.

Danilova E., Yadov V. (2010) Russian Labour Culture: How it Looks in Comparison // International Review of Sociology, vol. 20, no 1, pp. 143-160.

Grachev M. (2009) Russia, Culture, and Leadership: Cross-cultural Comparisons of Managerial Values and Practices // Problems of Post-Communism, vol. 56, no 1, pp. 3-11.

Hofstede G. (2001) Culture's Consequences: Comparing Values, Behaviors, Institutions and Organizations Across Nations, Sage Publications.

Hofstede G., Hofstede G.J., Minkov M. (2010) Cultures and Organizations. Software of the Mind, McGraw-Hill.

Hofstede G., Minkov M.(2013)VSM2013. Values Survey Module2013 Manual// Geert Hofstede // http://geerthofstede.com/research-and-vsm/vsm-2013

Kohun F.G., Skovira R.J., Burcik V., DeLorenzo G. (2014) Knowledge Management as a Sub-Culturally Bound Determinant - Redefining the Hofstede Hypothesis, Portoroz.

Kuchinke K.P. (1999) Leadership and Culture: Work-Related Values and Leadership Styles Among One Company's U.S. and German Telecommunication Employees // Human Resource Development Quarterly, vol. 10, no 2, pp. 135-154.

Lebedeva N., Tatarko A. (2012) Values of Russians: the Dynamics and Relations towards Economic Attitudes. WP BRP 03/SOC/2012, Moscow: HSE.

Magun V., Rudnev M., Schmidt P. (2016) Within-and Between-Country Value Diversity in Europe: A Typological Approach // European Sociological Review, vol. 32, no 2, pp. 189-202.

Nistor N., Lerche T., Weinberger A., Ceobanu C., Heymann O. (2014) Towards the Integration of Culture into the Unified Theory of Acceptance and Use of Technology // British Journal of Educational Technology, vol. 45, no 1, pp. 36-55.

Taras V., Steel P., Kirkman B.L. (2016) Does Country Equate with Culture? Beyond Geography in the Search for Cultural Boundaries // Management International Review, vol. 56, no 4, pp. 455-487.

\title{
The Industrial Culture of Modern Russian Workers as an Element of Their Human Capital: an Ethnometric Analysis Using Hofstede's Model
}

\author{
N. LATOVA*
}

*Nataliya Latova - Candidate of Science in Sociology, Senior Research Fellow, Institute of Sociology, Russian Academy of Sciences. Address: bld. 5, 24/35, Krzhizhanovskij St., Moscow, 117218, Russian Federation. Email: myshona@rambler.ru

Citation: Latova N. (2017) The Industrial Culture of Modern Russian Workers as an Element of Their Human Capital: an Ethnometric Analysis Using Hofstede's Model. Mir Rossii, vol. 26, no 3, pp. 36-63 (in Russian). DOI: 10.17323/1811-038X-2017-26-3-36-63

\section{Abstract}

This article studies the industrial culture of different occupational groups. Particular attention is paid to the industrial and organisational culture of people in working class 
occupations. The analysis is based on the ethnometric technique of Hofstede (Value Survey Module 1994).

The study reveals that Russians constitute a relatively homogeneous nation, which is almost equally distant from both Eastern and Western nations in its cultural characteristics. In spite of a certain amount of variation between different groups of workers, representatives of all major Russian classes of occupations - upper and lower grade professionals, manual and non-manual workers - are quite similar to each other, and at the same time quite distinct from representatives of same occupations in other countries. However, a certain degree of dissimilarity exists between these groups, on the one hand, and the group of entrepreneurs, self-employed and managers, on the other hand. The cultural characteristics of the latter are much closer to the ones observed in Western nations.

Russian workers are characterized by the following cultural peculiarities: high "Uncertainty Avoidance" (effective work is possible only when there are clear rules and minimised individual risk), low "Masculinity" (the importance of relationships in the team, the priority of maintaining a favourable production climate as opposed to achieving a result at any cost), average "Individualism" (the importance of linking the results of labour with the personal achievements of a particular employee) and low "Power Distance" (the desire to have accessible and equal leader).

Although distinct from their Western counterparts, Russian workers share some specific features with workers from other countries: they are more focused towards hierarchy and to a lesser extent are characterized by the presence of achievement motivations.

The specific industrial culture of Russian workers is also compatible with a specific form of work organization formed historically in Russia - artels. Russian industrial culture is also highly stable and therefore increasing productivity, economic efficiency and returns on the human capital of Russian workers would rely on more traditional forms of employment, rather than adopting new organizational models.

Key words: ethnometrics, industrial culture, human capital, workers, Hofstede, artel labour organization, Russian culture

\section{References}

Artel (1890) [Artel]. Entsiklopedicheskij slovar' Brokgauza i Efrona [Encyclopedic Dictionary by Brockhaus and Efron]. T. II. SPb.: Semenovskaya Tipolitografiya (I.A. Efrona), pp. 184-194.

Averyanov V. (2014) Russkaya artel. Nevostrebovannyj opyt: iz proshlogo v budushchee? [Russian Artel. Unclaimed Experience: From the Past to the Future]. Svobodnaya mysl', no 3, pp. 107-124.

Becker G. (2003) Chelovecheskoe povedenie: ekonomicheskij podkhod. Izbrannye trudy po ekonomicheskoj teorii [The Economic Approach to Human Behavior. Selected Writings on Economic Theory], Moscow: HSE.

Bushueva I.P., Bogdan N.N., Zubov V.E. (2014) Kar'iera v gosudarstvennoj grazhdanskoj sluzhbe: proshloe, nastoyashchee, budushchee [Career in Public Civil Service: Past, Present, Future]. Upravlencheskoe konsul'tirovanie, no 7 (67), pp. 7-18. 
Danilova E., Tararukhina M. (2003) Rossijskaya proizvodstvennaya kul'tura v parametrakh G. Hofshteda [Russian Industrial Culture Measured in G. Hofstede's Dimensions]. Monitoring obshhestvennogo mneniya, no 3 (65), pp. 53-64.

Danilova E., Yadov V. (2010) Russian Labour Culture: How it Looks in Comparison. International Review of Sociology, vol. 20, no 1, pp. 143-160.

Engelgardt A. (2010) Pis'ma iz derevni [Letters from the Countryside], Moscow: Algoritm.

Grachev M. (1999) Menedzhment v «mezhdunarodnoj sisteme koordinat» [Management in a World Landscape]. Ekonomicheskie strategii, no 2, pp. 19-31.

Grachev M. (2009) Russia, Culture, and Leadership: Cross-cultural Comparisons of Managerial Values and Practices. Problems of Post-Communism, vol. 56, no 1, pp. 3-11.

Harrison L., Huntington S. (eds.) (2002) Kul'tura imeet znachenie. Kakim obrazom cennosti sposobstvuyut obshhestvennomu progressu [Culture Matters: How Values Shape Human Progress], Moscow: Moskovskaya shkola politicheskikh issledovanij.

Hofstede G. (2001) Culture's Consequences: Comparing Values, Behaviors, Institutions and Organizations Across Nations, Sage Publications.

Hofstede G. (2014) Model Hofstede v kontekste: parametry kolichestvennoj kharakteristiki kul'tur [Dimensionalizing Cultures: The Hofstede Model in Context]. Yazyk, kommunikatsiya i sotsial'naya sreda, no 12, pp. 9-49.

Hofstede G., Hofstede G.J., Minkov M. (2010) Cultures and Organizations. Software of the Mind, McGraw-Hill.

Hofstede G., Minkov M. (2013) VSM 2013. Values Survey Module 2013 Manual. Geert Hofstede. Available at: http://geerthofstede.com/research-and-vsm/vsm-2013, accessed 31 May 2017.

Inglehart R. (2002) Kul'tura i demokratiya [Culture and Democracy]. Kul'tura imeet znachenie. Kakim obrazom tsennosti sposobstvuyut obshchestvennomu progressu [Culture Matters: How Values Shape Human Progress] (eds. Harrison L., Huntington S.), Moscow: Moskovskaya shkola politicheskikh issledovanij, pp. 106-128.

Inglehart R., Welzel C. (2011) Modernizatsiya, kulturnye izmeneniya $i$ demokratiya. Posledovatelnost' chelovecheskogo razvitiya [Modernization, Cultural Change and Democracy: The Path of Human Development Sequence], Moscow: Novoe izdatel'stvo.

Isaev A. (1881) Arteli v Rossii [Artel in Russia], Yaroslavl': Pechatnya Gubernskogo pravleniya. Kalachev N. (1864) Arteli v drevnej i nyneshnej Rossii [Artel in Ancient and Present-day Russia], $\mathrm{SPb}$.: Tipografiya V. Golovina.

Kohun F.G., Skovira R.J., Burcik V., DeLorenzo G. (2014) Knowledge Management as a Sub-Culturally Bound Determinant - Redefining the Hofstede Hypothesis, Portoroz.

Kuchinke K.P. (1999) Leadership and Culture: Work-Related Values and Leadership Styles Among One Company's U.S. and German Telecommunication Employees. Human Resource Development Quarterly, vol. 10, no 2, pp. 135-154.

Laboratory for Comparative Social Research. National Research University Higher School of Economics. Available at: http://lcsr.hse.ru, accessed 31 May 2017.

Latova N.V. (2003) Etnometricheskie izmereniya: teoriya i praktika [Ethnometrical Measurement: Theory and Practice]. Sotsiologiya: metodologiya, metody, matematicheskoe modelirovanie, no 17 , pp. 142-166.

Latova N.V. (1) (2016) Vliyanie krizisa na udovletvorennost' rossiyan svoej zhiznyu i ikh sotsial'no-psikhologicheskoe samochuvstvie [The Impact of the Crisis on the Life Satisfaction of Russians and Their Social and Psychological Well-being]. Rossijskoe obshchestvo i vyzovy vremeni. Kniga tretya [Russian Society and the Challenges of Time. Book Three] (eds. Gorshkov M.K., Tikhonova N.E.), Moscow: Ves’ Mir, pp. 41-65.

Latova N.V. (2) (2016) Kulturnaya spetsifika rossiyan (etnometricheskij analiz na osnove kontseptsii G. Xofsteda) [Russians' Cultural Specificity (An Ethnometrical Analysis Based on Geert Hofstede's Concept)]. Vestnik Instituta sotsiologii, no 4 (19), pp. 155-179.

Latova N.V., Latov Yu.V. (2001) Rossijskaya ekonomicheskaya mental'nost na mirovom fone [The Russian Economic Mentality in the World Context]. Obshchestvennye nauki $i$ sovremennost', no 4, pp. 31-43.

Latova N.V., Tikhonova N.E. (2010) Modernizatsiya i kharakteristiki rossijskoj natsional'noj mental'nosti [Modernization and Characteristics of the Russian National Mentality]. 
Gotovo li rossijskoe obshchestvo k modernizatsii? [Is Russian Society Ready to Upgrade?] (eds. Gorshkov M.K., Krumm R., Tikhonova N.E.), Moscow: Ves’ Mir, pp. 273-297.

Lebedeva N.M., Tatarko A.N. (2007) Tsennosti kul'tury i razvitie obshchestva [Cultural Values and Society Development], Moscow: HSE.

Lebedeva N., Tatarko A. (2012) Values of Russians: the Dynamics and Relations towards Economic Attitudes. WP BRP 03/SOC/2012, Moscow: HSE.

Magun V.S., Rudnev M.G. (2010) Bazovye tsennosti rossiyan i drugikh evropejtsev (po materialam oprosov 2008 goda) [Basic Values of Russians and Other Europeans: (According to the Materials of Surveys in 2008)]. Voprosy ekonomiki, no 12, pp. 107-130.

Magun V.S., Rudnev M.G., Schmidt P. (2015) Evropejskaya tsennostnaya tipologiya i bazovye tsennosti rossiyan [European Value Typology and Basic Values of Russians]. Vestnik obshchestvennogo mneniya. Dannye. Analiz. Diskussii, vol. 121, no 3-4, pp. 74-93.

Magun V., Rudnev M., Schmidt P. (2016) Within-and Between-Country Value Diversity in Europe: A Typological Approach. European Sociological Review, vol. 32, no 2, pp. 189-202.

Nistor N., Lerche T., Weinberger A., Ceobanu C., Heymann O. (2014) Towards the Integration of Culture into the Unified Theory of Acceptance and Use of Technology. British Journal of Educational Technology, vol. 45, no 1, pp. 36-55.

Platonov O.A. (1991) Russkij trud [Russian Labor], Moscow: Sovremennik.

Svedeniya o zarabotnoj plate rabotnikov organizatsij po kategoriyam personala i professionalnym gruppam rabotnikov za oktyabr' 2015 g. (statisticheskij byulleten') (2016) [Data on Wages of Employees by Type and Occupation of Employees in October 2015 (Statistical Bulletin)]. Federa' Inaya sluzhba gosudarstvennoj statistiki. Available at: http://www.gks.ru/wps/wcm/ connect/rosstat_main/rosstat/ru/statistics/wages/labour_costs, accessed 31 May 2017.

Shcherbina F. (1881) Ocherki yuzhno-russkikh artelei i obshchinno-artelnykh form [Essays on the South Russian Cooperatives and Communal-artel Forms], Odessa: Tipografiya G. Ulrixa.

Shkaratan O.I., Inyasevsky S.A. (2006) Sotsial'no-ekonomicheskoe polozhenie professionalov $\mathrm{i}$ menedzherov [The Socioeconomic Standing of Professionals and Managers]. Sotsiologicheskie issledovaniya, no 10, pp. 16-27.

Slobozhanin M. (1919) Novye postroeniya $v$ ideologii $i$ teorii kooperatizma-artelnosti [New Construction of Ideology and Cooperative-artel Theory], Petrograd: Tipografiya Petrogradskogo soyuza potrebitelskikh obshchestv.

Taras V., Steel P., Kirkman B.L. (2016) Does Country Equate with Culture? Beyond Geography in the Search for Cultural Boundaries. Management International Review, vol. 56, no 4, pp. 455-487.

Tsoj K., Lebedeva N.M., Tatarko A.N. (2016) Vzaimosvyaz' tsennostej i sotsial'noekonomicheskikh predstavlenij u korejskikh i rossijskikh studentov [The Relationship between Values and Socio-Economic Attitudes among Korean and Russian Students]. Psikhologiya. Zhurnal Vysshej shkoly ekonomiki, vol. 13, no 2, pp. 310-322.

Vorontsov V.P. (1895) Artel'nye nachinaniya russkogo obshchestva [Artel' Initiatives of Russian Society], SPb.: Tipografiya I.N. Skorohodova. 